\title{
Weight Bias in the Media: A Review of Recent Research
}

\author{
Rheanna N. Ata J. Kevin Thompson \\ Department of Psychology, University of South Florida, Tampa, FL, USA
}

\section{Key Words}

Obesity · Overweight · Psychological aspects .

Social determinants - Weight bias

\section{Summary}

Background: There is ample evidence that overweight and obese individuals are stigmatized in various forms of media. This weight bias is particularly disconcerting when it targets children and adolescents. Objective: The current review surveys the most recent 15 years of research on weight bias and stigmatization in the media and discusses some theoretical models that might help explain the negative effects of such material. Method: PsycINFO searches were conducted using weight biasand stigmatization-related terms and phrases. Results were limited to journal articles published in English between 1994 and 2009. Results: Overall, the data indicate that a wide range of media - from television shows to books, newspapers, and the internet - portray overweight and obese individuals in a stigmatizing manner. Conclusion: More research on this topic is needed to discern a direct connection between exposure to such material and psychological or physical harm to the viewer. Additionally, virtually all of the research has been conducted in the USA; research in other countries should be a top priority. Efforts to try to educate the media to the deleterious effects of media presentations of weight bias are indicated.

\section{Weight Bias in the Media}

The world is gaining weight. According to the World Health Organization's (WHO) projections, approximately 1.6 billion individuals (at least 15 years of age) were overweight in 1995 and about 400 million were obese [1], and this global trend in weight gain is expected to continue. By 2015, the WHO anticipates that 2.3 billion adults will be overweight and approximately 700 million will be obese. Overweight among children and adolescents has also increased dramatically over the decades. In 2005, at least 20 million children (under 5 years) were overweight [1]. In the USA alone, data from 2003-2006 revealed that the estimates of overweight were close to $19 \%$ for children and $17 \%$ for adolescents [2].

These increases in prevalence are particularly disconcerting given the myriad negative consequences of being overweight or obese. While some of these consequences are physiological (e.g. diabetes, hypertension), others are psychological (e.g. poorer body image) and have been linked to the increased social stigma and weight discrimination faced by individuals who are above 'normal' weight [3]. The terms weight bias and stigmatization have been used somewhat interchangeably in the research literature and have been generally defined as 'negative attitudes about individuals based on suppositions about a group they belong to' $[4$, p. 9]. Weight bias has been found to have negative effects on employment, education, health care [5], and interpersonal relationships [6]. Based on a cultural emphasis on thinness, beliefs in individual responsibility, and attributions of controllability [7, 8], weight bias has become a widespread, socially acceptable form of prejudice and discrimination [9]. Recently, research has begun to examine the presence of weight bias in the media.

Given the vast nature of the topic at hand and space limitations of this article, PsycINFO searches were conducted for journal articles published in English between 1994 and 2009 using the following terms and phrases: 'weight bias', 'weight stigmatization', 'fat stigmatization', 'fat bias', and 'fat stereotyping'. Searches were also conducted using the term 'media' in conjunction with 'weight', 'fat', and 'obesity'. Other empirical articles included in this review were either suggested during the review process or cited within another article and then searched for manually. In addition to summarizing the most

\begin{tabular}{ll}
\hline KARGER & $\oplus$ 2010 S. Karger GmbH, Freiburg \\
Fax +497614520714 & Accessible online at: \\
$\begin{array}{l}\text { Information@Karger.de } \\
\text { www.karger.com }\end{array}$ & www.karger.com/ofa
\end{tabular}


recent 15 years of empirical work in the area, we outline a few of the most relevant, frequently cited theoretical models and offer suggestions for future investigation in this review.

\section{Role of the Media in Perpetuating Weight Bias}

The media serve to influence, reflect, and reinforce social norms, attitudes, and beliefs about weight [10]. Weight bias is thought to be perpetuated by the media via i) idealization of body types that are inconsistent with being overweight and ii) under-representation and stereotyping of overweight and obese characters $[11,12]$. Body ideals portrayed in the media differ for females and males. According to the culturally defined, stereotypic images portrayed therein, females should be thin and males should be muscular [13]. Even though only $5 \%$ of women are actually underweight, almost a third of those portrayed on television are underweight [11]. Overweight and obese individuals, on the other hand, are severely under-represented on television $-13 \%$ of females and $24 \%$ of males on television are overweight or obese, as compared to $51 \%$ of females and $59 \%$ of males in the general US population [11]. When characters are portrayed as overweight or obese, they are commonly the targets of fat humor and stigmatization, as we outline below.

\section{Weight Bias in Child-Targeted Media}

\section{Animated Cartoons}

Although one might be tempted to equate physical attractiveness with body weight, it is 'entirely possible to be overweight and still very good-looking, or to be thin and unattractive' [14, p. 354]. Thus, in their follow-up content analysis of children's animated cartoons, Klein and Shiffman made a concerted effort to differentiate between the two [14]. The cartoons included in their study were randomly selected from all cartoons produced between 1930 and the mid-1990s (e.g. Bugs Bunny, Mighty Mouse). Major characters in all of the cartoons selected - including non-human characters - were first categorized in terms of their physical attractiveness as physically unattractive, average or normal looking, or physically attractive and then coded on other variables such as demographics, level of intelligence, marital status, body weight, social activities in which the character engaged, and number of violent, aggressive, and prosocial acts committed.

Results indicated that overweight characters were almost three times more likely to be classified as physically unattractive than underweight or normal-weight characters; underweight characters were two times more likely than heavier characters to be portrayed as attractive. Those deemed unattractive (i.e. primarily overweight characters) were significantly more likely to be depicted as less intelligent, loving, and physically healthy. They were also more commonly un- employed, unhappy, and angry. Consistent with the 'what is beautiful is good' stereotype [15, p. 285], unattractive characters were nine times more likely to be categorized as 'bad characters' who engaged in half as many prosocial acts and significantly more violent and aggressive acts than their better-looking counterparts. These results were also consistent with Klein and Shiffman's original content analysis [16].

\section{Situation Comedies}

As compared to animated cartoons and other forms of television programming, children's situation comedies seem to portray overweight characters in a more positive, less stereotypical fashion [17]. In a study designed to examine children's situation comedies and how characters of differing body weight are presented therein, researchers included all major and minor characters (ages 9-18 years) in shows broadcast on Nickelodeon (e.g. Drake and Josh, Zoey 101), the Disney Channel (e.g. That's so Raven, Hannah Montana), and Discovery Kids (e.g. Darcy's Wild Life, Flight 29 Down) [17]. Characters were coded in terms of their gender, ethnicity, body weight (using an adaptation of the Children's Body Image Scale; CBIS [18]), appearance, intelligence, popularity, activity level, personality type, leadership qualities, and physical characteristics.

In terms of body weight representation, characters tended to be average weight, followed by below-average and aboveaverage weight. It is important to note, however, that shows differed in their inclusion of below-average weight characters - from none (i.e. Sabrina the Teenage Witch, Boy Meets World, Life with Derek, and Naturally Sadie) to more than five (i.e. Ned's Declassified, Unfabulous, Zoey 101, Even Steven, Lizzie McGuire, and Flight 29 Down). Only one show (i.e. That's so Raven), which consists of a primarily AfricanAmerican cast, included more than five above-average weight characters. This is consistent with the finding that AfricanAmericans were more likely to be portrayed as above-average weight than their Caucasian counterparts, who tended to be average or below-average weight.

While most characters were judged as being 'attractive' or 'average,' and as having 'many friends' or 'a small group of friends,' those who were coded as 'unattractive' and as having 'no friends' tended to be above-average weight. $15 \%$ of all characters coded were classified as above-average weight. The fact that the national average in 2006 (for children and adolescents) was $17.1 \%$ led the researchers to conclude that children's sitcoms are, at the very least, making an effort to portray body weight in a realistic manner.

\section{Movies and Books}

Body image-related messages, which tend to associate beauty with thinness, are also present in children's movies and books [19]. In their content analysis of movies and books (for children ages 4-8 years), Herbozo and colleagues [19] examined the frequency of messages relating to physical attractiveness, 
beauty, body shape and size, thinness, muscularity, and obesity to negative (i.e. evil, unattractive, unfriendly, cruel) and positive (i.e. sociable, kind, happy, successful) traits. Results indicated that in $72 \%$ of the movies and $10 \%$ of the books, thin characters were associated with positive traits. In $64 \%$ of the movies and $20 \%$ of the books, obese characters - human and animal alike - were most often portrayed as possessing negative traits and, subsequently, tended to be disliked by others.

\section{Association between Media Use and Weight Bias}

Given the biased representation of overweight and obese individuals in child-targeted media, it is not surprising that children who are exposed to greater amounts of media express greater stigmatization of overweight people. In fact, children who report greater total media use, magazine use, and time spent playing video games evidence greater stigmatization of overweight and obese children than their peers who consume less media [20]. When third graders were presented with images of a thin girl, a fat girl, a thin boy, and a fat boy and asked to describe each in terms of a number of characteristics, males were more likely to stereotype the fat boy and significantly more likely to stereotype the fat girl than females [21]. Only fat girl stereotyping among males was associated with greater time spent watching television. Decreased fat boy stereotyping for both males and females and fat girl stereotyping among females were associated with liking, feeling similar to, and wanting to be like (i.e. interpersonal attraction to) fat male characters. Interpersonal attraction to fat female characters, on the other hand, was lower and seemingly unrelated to stereotyping. Harrison concluded that this was because 'they (fat female characters) are so negatively portrayed that even the most accepting of children tend to remain unattracted to them' [21, p. 635].

In a more recent study, similarly aged participants were shown figures of six boys and six girls and asked to rank them in order of liking [20]. They were also asked a series of questions about the obese figures, in an attempt to measure obesity-stigmatizing attitudes. Each set of figures - regardless of the child's sex - included a normal-weight child, an overweight child, a child on crutches, a child in a wheelchair, a child with a missing hand, and a child with a facial scar. Endorsement of more stigmatizing attitudes was associated with increased weekday video game playing and total media use. In boys, it was also associated with total time spent watching television. Liking of the obese figures (compared to the nonobese figures) was negatively related to magazine use, which tended to be higher among girls.

\section{Weight Bias in Adolescent- and Adult-Targeted Media}

\section{Situation Comedies and Movies}

Overweight sitcom characters are less likely than their normal-weight or underweight counterparts to be judged as at- tractive and tend to have fewer interactions with friends or romantic partners [11]. Larger male characters, in particular, are less likely to date and have sex, whereas larger female characters are more likely to be the targets of humor. For males, being thin tends to be more detrimental than being overweight when it comes to being ridiculed. While being above normal weight is most stigmatizing for females, any deviation from the norm (i.e. below or above) can lead to stigmatization and ridicule of males [11].

Results from a series of content analyses by Fouts and Burggraf $[22,23]$ provide further support for the notion of thinness as a protective factor for female sitcom characters. In their analysis of 52 female characters from 28 different primetime situation comedies, Fouts and Burggraf [22] found that thinner female characters received more positive comments from males than their heaver counterparts. In terms of negative comments, there was a significant positive correlation between the weight of a female character and the frequency of negative comments she received [23]. Thus, heavier characters tended to receive more negative comments than thinner characters. Furthermore, the derision of heavier females by males was reinforced by positive audience reactions (i.e. laughter) $80 \%$ of the time [23]. In a similar content analysis of male characters, heavier males made more negative comments about themselves, but were no more likely to receive such comments from females than their thinner counterparts [24]. Even on the rare occasion when negative comments were directed toward heavier males, they were not reinforced by audience laughter.

In 2007, Himes and Thompson [12] took a closer look at fat-related commentary and humor in television shows and movies (from 1984-2004). Each fat stigmatization vignette was coded according to gender and age of the commentator and target, whether the comment was direct (i.e. target was present) or indirect (i.e. target was absent), and whether the comment was communicated verbally or non-verbally. Results revealed that adult males were the most frequent perpetrators of fat commentary, the majority of which was direct and verbal. Although some of the commentary was self- or group-directed, most of it was directed at individual targets. These individual targets were most likely to be adults, with males receiving negative commentary $49 \%$ of the time and females receiving negative commentary $45 \%$ of the time.

\section{Weight Loss Programming}

Television also contains programming related to losing weight; typically a so-called scientific expert in a white labcoat is touting the benefits of a particular weight loss drug while 'before' and 'after' shots of individuals in swimwear are being flashed on the screen. Sometimes there are testimonials from satisfied customers. And, occasionally, there is even a celebrity endorsement (e.g. Marie Osmond for NutriSystem, Kirstie Alley for Jennie Craig and, most recently, Wynnona Judd for Alli). 
While their overt purpose is to increase product sales, weight loss infomercials and advertisements also serve to promote gender and weight-related stereotypes [25] and perpetuate the belief that weight is controllable [26]. In weight loss infomercials, in particular, the scientific expert is usually a male [25]. The vast majority of the hosts and satisfied customers, on the other hand, are females, which serves to reinforce the common misperception that weight is a 'woman's issue'. An examination of the 'before' and 'after' images of these satisfied customers revealed that they tend to look happier in the 'after' as compared to the 'before' images. Viewers may take note of this difference in emotion and conclude that if you are heavy, you must be unhappy', but 'losing weight will make you happy' [25, p. 355]. Moreover, according to the testimonials, losing weight is easy - 'no diet or exercise required'!

The media also suggest that losing weight will make you more attractive. In another study designed to examine 'before and after' diet advertisements, participants were randomly assigned to one of three groups: 'before and after' pictures, 'before' picture only, or 'after' picture only [26]. Participants who were shown either the 'before' or 'after' picture (which had been embedded into a different ad) tended to rate the woman as more attractive in their respective pictures than those who were presented with 'before and after' pictures. According to what the researchers termed 'the caterpillar to butterfly effect' [26, p. 287], an appealing future can make a currently overweight individual appear more attractive, but an overweight past can diminish current attractiveness.

\section{Reality Television}

The advent of television touted to provide viewers with an unscripted, uncensored look at the lives of 'real' people has brought with it a number of weight-related reality television shows. Some of these shows encourage competition between two groups of overweight individuals vying to collectively lose the most weight; others pit overweight women against each other in the quest for the attention of a bachelor (who also happens to be overweight) and a possible marriage proposal. Regardless of their specific focus, these shows have the ability to educate the public on the 'struggle' many overweight and obese individuals face as they strive to achieve and maintain a healthy weight and lifestyle [27].

In practice, however, weight-related reality television shows have yet to provide a positive, humanizing portrayal of obesity. In one qualitative study, 76 obese Australians were asked about their attitudes and opinions in regards to the show The Biggest Loser [28]. Results indicated that approximately $71 \%$ of the participants had negative views about the show's basic concept. More specific criticisms included: i) portraying an unrealistic, unhealthy, and unaffordable solution to obesity; ii) emphasizing weight loss and thinness over healthy lifestyle changes; iii) reinforcing stereotypes of obese people as 'lazy' and 'unmotivated', and iv) reinforcing the belief that individuals are to blame for obesity.

\section{YouTube}

YouTube (www.YouTube.com) is one of the most popular video-sharing websites. The advent of this popular site has allowed for unprecedented widespread communication of ideas, attitudes, and behaviors. Among such attitudes and behaviors presented on the site and, therefore, accessible to over a billion users per day [29], are weight bias and stigmatization. A recent qualitative analysis of fat stigmatization on YouTube examined the 50 most viewed videos that contained 'fat stigmatization' in the title, video, and/or comments [30].

Results indicated that both antagonists and targets of fat stigmatization tended to be white, adult males. In fact, males were almost twice more likely to be targets, and over twelve times more likely to be antagonists, than females. Children and adolescents were also portrayed as targets and antagonists of fat stigmatization, although to a lesser degree. What is perhaps most disturbing is the fact that people are watching and enjoying these videos. The videos, on average, were given 4.13 stars out of 5 and had been viewed by over 2,000,000 people.

\section{News Coverage}

In order to present information in a manner that can be understood by the majority of consumers, the news media engage in framing - the process whereby certain topics or issues are emphasized, while others are deemphasized or ignored [31]. Depending on how they choose to 'frame' obesity, the news media can have adverse effects on individuals' perceptions of overweight and obese people.

Although obesity has been linked to a number of psychosocial, behavioral, genetic, and environmental factors [32], the news media tend to place the blame on individuals [33] by overemphasizing personal causes (e.g. unhealthy diet, lack of physical activity). In fact, one study that sought to analyze the portrayal of obesity in US newspaper and television news found that 'unhealthy diet,' followed by 'sedentary lifestyle,' was implicated most often as a cause of obesity [34]. In Australian television news, 'nutrition' is frequently labeled as the most important cause of overweight and obesity [35].

The portrayal of obesity in print news appears to be dependent on the type of newspaper. In 2009, Hilbert and Ried [36] systematically searched all issues of five German daily newspapers for terms related to obesity. Comparisons among national newspapers, local newspapers, and a tabloid newspaper revealed that the former two provided a more comprehensive and accurate account of obesity than the latter. Regardless of the type of newspaper, minimal information regarding the definition and prevalence of obesity was provided. This is particularly problematic, as a dearth of information on obesity has been linked to increased stigmatizing attitudes [37]. Furthermore, although the national newspapers offered the broadest coverage on the topic, they were also responsible for providing the highest number of internal attributions. 
Given that the news media tend to frame the problem of obesity as one of personal responsibility, it should come as no surprise that person level solutions (e.g. healthy diet, increased physical activity, surgical/medical treatment) are presented more frequently than society level solutions (e.g. changes in school lunches, regulation of advertising/food industry) $[34,35]$. It is important to note, however, that there has been a recent increase in references to societal causes and solutions [34], which may lead to changes in the perception of obesity and the conceptualization of interventions designed to decrease its prevalence.

\section{Theoretical Approaches to Understanding the Effects of Weight Bias in the Media}

A number of different theories have been posited to explain how weight bias presented in the media may affect children, adolescents, and adults (refer to Puhl and Brownell's review [38] for a more comprehensive overview of theories offered to explain weight stigma). Attribution theory, for example, has been used to explain the deleterious effects of overemphasis of personal causes of obesity on stigmatizing attitudes. According to attribution theory [39], outcomes - such as obesity - can be thought of as a result of either internal, controllable causes or external, uncontrollable causes. Whether obesity is perceived to be the result of internal or external causes can affect subsequent attitudes about and reactions to obese individuals. Recent research has supported the idea that stigmatizing and negative attitudes towards obese individuals tend to be greater when obesity is attributed to internal, controllable causes (e.g. poor diet, lack of willpower) as opposed to external causes beyond the individual's control (e.g. a thyroid condition) [7, 37, 40-42].

According to Fouts and Burggraf [22], the media provide viewers with information on acceptability of behavior and body weight by means of modeling and vicarious positive reinforcement and punishment. Thus, seeing a thin character receive positive reinforcement or seeing a heavier character receive negative weight-related comments may lead to increases in internalization of the thin ideal and body dissatisfaction. This is consistent with sociocultural models that posit that the media has both direct and indirect (i.e. via appearance comparison and internalization) on body dissatisfaction [43]. Furthermore, the stigmatization and ridiculing of heavier characters is typically followed by positive audience reactions, which serve to reinforce - and perhaps even condone - the use of such behaviors [23].

Social consensus theory, which emphasizes the importance of perceived consensus in the expression of discriminatory attitudes [44], has also been cited to explain how the media may perpetuate weight bias. In forming their beliefs and attitudes about overweight individuals, those exposed to the media may fail to consider real-life experiences and interactions with such individuals and, instead, rely solely on the perceived beliefs of others [38]. The frequent stigmatization of overweight and obese individuals in the media may lead viewers to 'overestimate the degree that others share negative beliefs about obese individuals and in turn express biased stereotypes' [38, p. 222].

\section{Future Research}

This review was designed as a targeted content analysis of research on media-presented weight bias that has been reported over the past 15 years, with a selective focus on the primary theoretical approaches and analysis of major publications in the area. There are many avenues for future work in this area. For instance, content analyses might focus on adult's (as opposed to children's) animated cartoons. Data collected by Nielsen Media Research suggest that although cartoons such as The Simpsons, Family Guy, and American Dad are blatantly adult-themed, they are among the top 20 most popular prime-time TV shows watched by children and adolescents between the ages of 2 and 17 [45]. How prevalent is weight stigmatization in such shows? And what effects might it have on younger viewers? A particularly salient commonality between The Simpsons and Family Guy, for example, is the pairing of an overweight male (of questionable intelligence) with a thin, attractive female. Why are overweight males commonly married to thin, attractive females, but not vice versa? What messages do such pairings send viewers about stereotypes and gender differences in the acceptability of overweight?

Future research on weight bias in the media should also examine possible moderating effects of ethnicity and age. In 1980, Kaufman [46] found that $90 \%$ of African-American characters on television were portrayed as obese. Is the percentage similar today? Might the fact that African-Americans are more commonly portrayed as overweight than their Caucasian counterparts be associated with ethnic differences in terms of viewer resilience and risk? In terms of potential developmental differences, is there a period at which individuals are particularly susceptible to the effects of the media? Additionally, to date, content analyses have been conducted on US media; it would be important to look at media in other countries. Experimental research on the topic of media weight bias needs to be conducted in order to examine the immediate effects of exposure to weight bias on self-esteem and body dissatisfaction among viewers of differing body weights. It might also be interesting to design a social experiment to determine the effects of weight-related information (as portrayed in photographs) displayed on Facebook and other social networking sites on university admittance and hiring practices.

Given the particular sensitivity of such stigmatization on younger viewers, it will be important to continue to investigate children and adolescents. For instance, studies designed 
to evaluate the possible positive impact of having an overweight or obese young person who is portrayed in a positive manner are indicated as well as whether the viewer responds differently to someone who suffers stigmatizing feedback and shows the psychological consequences of such an experience. Finally, it may be time to consider the merits of direct intervention with media corporations to try to reduce the level of weight bias portrayed in the media. Activistic strategies through letter or email contact or other avenues of public pressure (e.g. product boycotting) have often been successful in changing unacceptable media representations that reinforce racism and sexism. Perhaps it is time for these same strategies to be used to attack weightism.

\section{Disclosure}

The authors declared no conflicts of interest

\section{References}

1 World Health Organization: Obesity and Overweight. Geneva, World Health Organization, 2006. www.who.int/mediacentre/factsheets/fs311/en/index. html (accessed August 2009).

2 National Center for Health Statistics: Health, United States, 2008 with chartbook. Atlanta Centers for Disease Control and Prevention, 2009. www.cdc.gov/nchs/data/hus/hus08.pdf\#075 (accessed April 2009).

3 Annis NM, Cash T, Hrabosky JI: Body image and psychosocial differences among stable average weight, currently overweight, and formerly overweight women: the role of stigmatizing experiences. Body Image 2004;2:155-167.

4 Brownell KD: Introduction: the social, scientific, and human context of prejudice and discrimination based on weight; in Brownell KD, Puhl RM, Schwartz MB, Rudd L (eds): Weight Bias: Nature, Consequences, and Remedies. New York, Guilford Press, 2005, pp 1-14.

$\checkmark 5$ Puhl R, Brownell KD: Bias, discrimination, and obesity. Obes Res 2001;9:788-805.

6 Gortmaker A, Must A, Perrin JM, Sobol AM, Dietz WH: Social and economic consequences of overweight in adolescence and young adulthood. N Engl J Med 1993;329:1008-1012.

$\checkmark 7$ Crandall CS: Prejudice against fat people: ideology and self-interest. J Pers Soc Psychol 1994;66:882884.

8 Crandall CS, Martinez R: Culture, ideology, and antifat attitudes. Pers Soc Psychol Bull 1996;22: $1165-1176$.

9 Falkner NH, French SA, Jeffery RW, NeumarkSztainer D, Sherwood NE, Morton N: Mistreatment due to weight: prevalence and sources of perceived mistreatment in women and men. Obes Res 1999;7:572-576.

10 Thompson JK, Herbozo SM, Himes SM, Yamamiya Y: Weight-related teasing in adults; in Brownell KD, Puhl RM, Schwartz MB, Rudd L (eds): Weight Bias: Nature, Consequences, and Remedies. New York, Guilford Press, 2005, pp 137-149.

11 Greenberg BS, Eastin M, Hofschire L, Lachlan K, Brownell KD: Portrayals of overweight and obese individuals on commercial television. Am J Public Health 2003;93:1342-1348.

12 Himes S, Thompson, JK: Fat stigmatization in television shows and movies: a content analysis. Obesity 2007;15:712-718.

13 Ricciardelli LA, McCabe MP: Sociocultural and individual influences on muscle gain and weight loss strategies among adolescent boys and girls. Psychol Schools 2003;40:209-224.
14 Klein H, Shiffman KS: Messages about physical attractiveness in animated cartoons. Body Image 2006;3:353-363.

15 Dion K, Berscheid E, Walster E: What is beautiful is good. J Pers Soc Psychol 1972;24:285-290.

16 Klein H, Shiffman KS: Thin is 'in' and stout is 'out': what animated cartoons tell viewers about body weight. Eat Weight Disord 2005;10:107-116.

17 Robinson T, Callister M, Jankoski T: Portrayal of body weight on children's television sitcoms: a content analysis. Body Image 2008;5:141-151.

18 Truby H, Paxton SJ: Development of the children's body image scale. Br J Clin Psychol 2002;41:185203.

19 Herbozo S, Tantleff-Dunn S, Gokee-LaRose J, Thompson JK: Beauty and thinness messages in children's media: a content analysis. Eat Disord 2004:12:21-34.

20 Latner JD, Rosewall JK, Simmonds MB: Childhood obesity stigma: association with television, videogame, and magazine exposure. Body Image 2007;4:147-155.

21 Harrison K: Television viewing, fat stereotyping, body shape standards, and eating disorder symptomatology in grade school children. Commun Res 2000;27:617-640.

22 Fouts G, Burggraf K: Television situation comedies: female body images and verbal reinforcements. Sex Roles 1999;40:473-481.

23 Fouts G, Burggraf K: Television situation comedies: female weight, male negative comments, and audience reactions. Sex Roles 2000;42:925-932.

24 Fouts G, Vaughan K: Television situation comedies: male weight, negative references, and audience reactions. Sex Roles 2002;46:439-442.

25 Blaine B, McElroy J: Selling stereotypes: weight loss infomercials, sexism, and weightism. Sex Roles 2002;46:351-357.

26 Geier AB, Schwartz MB, Brownell KD: 'Before and After' diet advertisements escalate weight stigma. Eat Weight Disord 2003;8:282-288.

27 Stein K: When overweight and obesity become 'reality'. J Am Diet Assoc 2007;107:1706-1710.

28 Thomas S, Hyde J, Komesaroff P: 'Cheapening the struggle:' obese people's attitudes towards The Biggest Loser. Obes Manage 2007;3:210-215.

29 Hardy Q, Hessel E: GooTube. Forbes Magazine, 2006. www. forbes.com/forbes $/ 2008 / 0616 / 050 . \mathrm{html}$ (accessed April 2009).

30 Hussin MG, Frazier SN, Thompson JK: Fat stigmatization on YouTube: a content analysis (unpublished manuscript). Tampa, University of South Florida, 2009.
31 Entman RM: Framing: toward a clarification of a fractured paradigm. J Commun 1993;43:51-58.

32 Ludwig DS, Gortmaker SL: Programming obesity in childhood. Lancet 2004:363:226-227.

33 Boero N: All the news that's fat to print: the American 'obesity epidemic' and the media. Qual Sociol 2007;30:41-60.

34 Kim S-H, Willis LA: Talking about obesity: news framing of who is responsible for causing and fixing the problem. J Health Commun 2007;12:359-376.

35 Bonfiglioli MF, Smith BJ, King LA, Chapman SF, Holding SJ: Choice and voice: obesity debates in television news. Med J Aust 2007;187:442-445.

36 Hilbert A, Ried J: Obesity in print: an analysis of daily newspapers. Obes Facts 2009;2:46-51.

37 Hilbert A, Rief W, Brähler E: Stigmatizing attitudes towards obesity in a representative population-based sample: prevalence and psychosocial determinants. Obesity 2008;16:1529-1534.

38 Puhl RM, Brownell KD: Psychological origins of obesity stigma: toward changing a powerful and pervasive bias. Obes Rev 2003;4:213-227.

39 Weiner B, Perry RP, Magnusson J: An attributional analysis of reactions to stigmas. J Pers Soc Psychol 1988;55:738-748.

40 DeJong W: The stigma of obesity: the consequences of naïve assumptions concerning the causes of physical deviance. J Health Soc Behav 1980;21:75-87.

41 DeJong W: Obesity as a characterological stigma: the issue of responsibility and judgments of task performance. Psychol Rep 1993;73:963-970.

42 Puhl RM, Schwartz MB, Brownell KD: Impact of perceived consensus on stereotypes about obese people: a new approach for reducing bias. Health Psychol 2005;24:517-525.

43 Thompson JK, Heinberg LJ, Altabe M, TantleffDunn S: Exacting beauty: theory, assessment, and treatment of body image disturbance. Washington DC, American Psychological Association, 1999.

44 Stangor C, Sechrist GB, Jost JT: Changing racial beliefs by providing consensus information. Pers Soc Psychol Bull 2001;27:486-496.

45 Parents Television Council: What are your children watching? Rating the top 20 most popular primetime broadcast TV shows watched by children ages 2-17. Parents Television Council, 2008. http://www. parentstv.org/ptc/publications/reports/top10bestandworst/2008/ptcwatchingguide08.pdf (accessed Nov 2009).

46 Kaufman L: Prime-time nutrition. J Commun 1980; 30:37-46. 